Revista Española de Antropología Americana ISSN: 0556-6533

http://dx.doi.org/10.5209/reaa.64172

\title{
La traducción de las especies eucarísticas al náhuatl: un episodio de la historia de la traducción en Nueva España
}

\author{
Miguel Figueroa Saavedra ${ }^{1}$
}

Recibido: 6 de mayo de 2019 / Aceptado: 24 octubre de 2019

Resumen. En este estudio de caso sobre el desarrollo de la traducción transcultural en la evangelización, se presentan las estrategias y criterios que emplearon los religiosos católicos para traducir el pan y el vino eucarístico a la población nahuahablante entre los siglos XVI y XIX.

Palabras clave: náhuatl; evangelización; eucaristía; lingüística misionera; traducción transcultural.

[naw] In tlahtolkuepalistli tlen itlakual, itlail Teotlasohkamatilistli ika nawatlahtolli: se yewehkatlahtolli itech tlahtolkuepalistli ipan Yankuik Kaxtillan

Se ome tlahtolli. Niknextia se tlatemolistli itech ken in traskultural tlahkuilolistli omochih kemman in tekristianotilistli okatka. Nikan moitta kenin iwan tleika in katolikomeh teopixkeh okitlahtolkuepkeh in tlaxkalli iwan wino tlen Teotlasohkamatilistli ipampa in nawatlahtohkeh ipan 16 xiwilpilli kampa 19 xiwilpilli.

Tlayakanki tlahtolli: nawatlahtolli; tekristianotilistli; Teotlasohkamatilistli; teopixkatlahtolmatilistli; traskoltoral tlahtolkuepalistli

\section{[en] The Translation of the Eucharistic Species into Nahuatl: An Episode from the History of Translation in New Spain}

Abstract. This case study on the development of transcultural translation in evangelization shows strategies and criteria used by Catholic religious to translate the Eucharistic bread and wine to the Nahuatl speaker people between the $16^{\text {th }}$ and $19^{\text {th }}$ centuries.

Keywords: Nahuatl; evangelization; eucharist; missionary linguistics; transcultural translation.

Sumario: 1. Introducción. 2. La traducción en la evangelización de América. 3. La traducción de las especies eucarísticas a la comunidad nahua. 4. La presentación de los dones: El pan y el vino como alimento material. 5. La comunión de dos especies: el pan y el vino como alimento espiritual. 6. Conclusiones. 7. Referencias.

$1 \quad$ Universidad Veracruzana, México.migfigueroa@uv.mx 
Cómo citar: Figueroa Saavedra, Miguel. 2020. "La traducción de las especies eucarísticas al náhuatl: un episodio de la historia de la traducción en Nueva España". Revista Española de Antropología Americana 50: 103-123.

\section{Introducción}

El presente trabajo ${ }^{2}$ quiere ahondar en el estudio de la historia de la traducción, tanto como el desarrollo de la metodología de la misma y las reflexiones teóricas que hayan podido establecerse a partir de su práctica (Hurtado 2008: 100), como un procedimiento de comunicación transcultural en contextos concretos. Este propósito implica reconocer, como arranque, la dificultad e inviabilidad de un acercamiento general, e igualmente la necesidad de romper con una visión estática y eurocéntrica de la traducción (Sabio 2006: 23), lo cual en los estudios históricos se ve limitado por el tipo y carácter de las fuentes, además de por los modos de lectura.

Con tal fin, me detendré en un episodio concreto que, como estudio de caso, es significativo por su complejidad y dinamicidad. Este caso es el proceso de evangelización y catequización de la población indígena de México entre los siglos XVI y XIX, y más concretamente la traducción de las especies eucarísticas al náhuatl en una época donde los aspectos teóricos, metodológicos e ideológicos de la traducción fueron objeto de controversia política-religiosa con la aparición del Humanismo (cfr. Hurtado 2008: 107-108). El resultado de estas guerras de traducción fue la defensa de la naturalización, de la adaptación lingüística hacia una fidelidad multidimensionada expresada en traducciones libres o comunicativas cuyo sentido y estilo debían guiarse más hacia la comprensión del significado que hacia la equivalencia formal, eludiendo la oscuridad de las formas y la extrañeza de la traducción de verbo ad verbum (Kelly 1979; Hurtado 2008: 108). Éste sería el punto de partida para saber si en el contexto americano hubo un desarrollo particular de estrategias de acomodación cultural y negociación lingüística en lo que fue el acercamiento a las lenguas y culturas mesoamericanas, y la formalización de un lenguaje litúrgico nahua cristiano.

\section{La traducción en la evangelización de América}

Dentro de la historia de la traducción, la evangelización en América se afirma como proceso de traducción transcultural paradigmático. No obstante, a pesar de prestársele atención en sucesivos congresos y publicaciones sobre lingüística misionera (Zwartjes y Hovdhaugen 2004; Zimmermann 2005; Zimmermann y Kellermeier-Rehbein 2015), este tema se limita a estudios comparativos o se diluye en aportaciones que abordan este proceso en otras regiones y continentes. Incluso en el ámbito hispano, aunque recientemente se sucedieron publicaciones y simposios (Vega 2012;

Este artículo es fruto de la colaboración con el proyecto de investigación "Investigación-sistematización de experiencias educativas de traducción y comunicación intercultural en los Talleres de lengua y cultura náhuatl del Equipo Nacional de Traductores del Náhuatl (ENTN) de la Conferencia del Episcopado Mexicano (CEM)" (UV-280732018111) del cuerpo académico Estudios Interculturales, liderado por la Dra. Irlanda Villegas Salas. 
Bueno 2013), la mayoría de los estudios sobre la evangelización en Hispanoamérica reivindican el papel protagónico de las órdenes religiosas, y visibilizan la figura y producción del traductor sin abordar directamente cuestiones lingüísticas o sociolingüísticas. No obstante, trabajos recientes (Bueno 2007; Payás 2010; Zamora 2012; Zwartjes 2016; Murillo et al. 2018) permiten ver desde otras posturas la historia de la traducción como un fenómeno que afronta desafíos comunicativos para construir nuevas identidades étnicas, generar diálogos interculturales, y renovar y actualizar las lenguas y la semiosis en contextos no ajenos al conflicto, donde la traducción se manifiesta como apropiación y resignificación recíproca de elementos culturales (Parodi 2009; Fountain 2015).

Este proceso se ha definido tradicionalmente como un "sincretismo", una "mezcla entre dos o varias civilizaciones (o culturas) que, después de enfrentarse, se enlazan" o como "respuestas autonomistas contra la hegemonía cultural colonialista implantada por las clases dominantes" (Báez-Jorge 2011: 202). Desde el marco de unas relaciones de poder asimétricas, hegemonía cultural y control institucional, la conversión religiosa no se muestra solo como asimilación o eliminación gradual de lo ajeno. Como proceso dialógico, dialéctico, la cultura autóctona describe reacciones diferentes ante el colonialismo, desde tratar de fortalecerse como una tradición continuista, a renovarse transformando ventajosamente los aspectos ineficientes, o adueñarse del poder del sistema religioso dominante reinterpretando ciertos rasgos en un sentido pagano, nativista o autonomista (Báez-Jorge 2011: 203). Considerar estas posibles reacciones para dar una continuidad identitaria y de existencia nos introduce en un marco complejo de dúplices identidades y pertenencias, de expectativas y memorias encontradas.

Esta situación conformó por varios siglos lo que Lockhart (1999) nombró double mistaken identity, y que en el plano traductivo puede expresarse como una double mistaken identification textual. Si en el primer caso muestra acomodo a los usos y elementos sociales de los viejos o propios sentidos otorgados a las prácticas y discursos que conformaron las relaciones entre las repúblicas de indios y de españoles, y la incorporación de los señoríos indígenas al dominio de la Corona hispánica y la Iglesia católica, en el segundo caso tenemos diferentes lecturas e interpretaciones de los elementos que articulan estos discursos y prácticas como una realidad textual, y que nos explican la génesis de la comunidad cristiana nahua.

En lo que es meramente el contacto de lenguas, esto se refleja en el cambio lingüístico y en lo que Claudia Parodi llama re-creación del signo lingüístico en un signo bicultural que "amplía su tipo cognitivo y su contenido nuclear para nombrar un referente o denotatum de una cultura distinta de la lengua original" (Parodi 2009: 26). Como acomodación semántica, supone la indianización del español arraigado en tierras americanas y la hispanización del indígena inserto en el área de dominación colonial; pues, desde la experiencia compartida, sus signos lingüísticos extienden su semántica para apropiarse verbal y conceptualmente de una nueva realidad, sin requerir del préstamo o del neologismo. Esto ocurre donde la asociación metafórica logra establecer una equivalencia (Parodi 2009: 29), y eso resulta más viable en realidades objetivables que en no objetivables, como los dogmas y conceptos cristianos.

Esto nos sirve para atisbar la complejidad e historicidad del proceso traductivo evangelizador que nos devela que en la comunicación entre ambos interlocutores (dominado y dominador) no siempre se comparten los mismos significados, lo que 
implica que los sistemas simbólicos tengan "zonas de significación insuficientemente definidas que contribuyen al desarrollo de la creatividad y a interpretaciones particulares de los sujetos vinculados en la red" (Báez-Jorge 2011: 203). Esto lleva ineludiblemente a una "nueva zona de significado" donde se identifican fenómenos de enmascaramiento por los dominados mediante el "disfraz lingüístico" y la "reinterpretación simbólica” (Bartolomé y Barabas 1982). Así, lo que autores como Antonio Bueno califican de "mestizaje textual" o "traducción mestiza" nos introduce en un problema traductológico y cultural que nos regresa a lo planteado por Félix Báez sobre el acercamiento antropológico al proceso de conversión sincrética o híbrida. Antonio Bueno expone al respecto de las traducciones agustinas:

"La traducción mestiza es un encuentro de conciencias lingüísticas, religiosas, etc., que se sirve de procedimientos comunicativos bilaterales y produce un pretendido efecto sobre el receptor. Hace décadas se acuñó el término de "aculturación” para expresar los variadísimos fenómenos que se originaban en Cuba "por las complejísimas transmutaciones e culturas que aquí se verifican, (...) a este término han seguido el de 'transculturación' y también de “inculturación”, como procesos de exportación o de inserción progresiva de una cultura concreta en otra" (Bueno 2007: 36-37).

Esta visión nos ayuda a entender el complejo marco en el que se ubicó la traducción del evangelio, el catecismo y la liturgia cristiana, y a comprender qué quiere y cómo cree el traductor estar dándolos a entender al neófito amerindio. De inicio fue un camino tortuoso, lleno de barreras, torpezas e incertidumbres, pues "había que hacer pasar a las lenguas indígenas nociones jamás por ellas dichas y para las cuales no era fácil hallar expresión" (Ricard 2001: 129-130). Según Robert Ricard, este objetivo se resolvería de dos maneras: "unos introducen en la lengua del país las palabras europeas que les parecen necesarias; otros, al contrario, traducen las palabras, si es posible, o expresan las nociones mediante perífrasis" (Ricard 2001: 130). Estas dos opciones aún hoy se consideran las estrategias básicas en la traducción evangelizadora (Zamora 2012: 113); pero ni siquiera, como señala Ricard, se da una oposición entre ambas opciones, y en muchas ocasiones se combinan. Además, surgen otras estrategias que nacen precisamente de la colaboración y el conocimiento estrecho y cercano de ambas comunidades, la conversora y la conversa.

Así, estas primeras opciones son un acercamiento primario y unidireccional, asumidas al inicio, cuando no había un interlocutor empático, receptivo ni dialogante. Pero ciertamente, como veremos en la traducción de las especies eucarísticas, el proceso no puede considerarse una imposición de significados, sino que también implicó transformar los sentidos propios de ambas partes. Como Fountain afirma sobre las traducciones de Sahagún: "As they attempted to transform and assimilate native cultures and languages into the fold of Christianity, so they found themselves changed and at times ever assimilated by their intimate knowledge of indigenous languages" (2015: 194). Evidentemente hubo un diálogo, al menos una preocupación por la recepción comprensiva, pues ambas opciones podrían generar desviaciones en la intención y uso original de los textos fuente. En el primer caso se necesitaba hacer accesible la semántica de las nuevas palabras como términos específicos a la espera de irse incorporando como palabras comunes. No obstante, podían darse asociaciones con palabras autóctonas. La adopción de palabras preexistentes debía asegurar que la 
carga semántica ya poseída no dificultara discernir los nuevos sentidos introducidos, pues, según fuera la intención comunicativa, la ambivalencia produciría "confusiones" o "interferencias" (Zamora 2012). Ambas opciones no estuvieron exentas de riesgos, sobre todo si se presentaba "la nueva religión como algo venido de fuera, algo que no pertenece a los indígenas, por lo que el cristianismo se consideraría una religión de extranjeros" (Zamora 2012: 113).

Por todo ello, serían muchas más las estrategias traductivas puestas en marcha. Zamora (2012: 115) y Zwartjes (2016) identifican que, ante la disparidad léxica y semántica, los términos "problemáticos" se resolverían mediante: 1) omisión de términos-conceptos del texto original, 2) préstamo o adopción de palabras de la lengua de traducción, 3) transferencia de palabras del texto original, castellano o latín, 4) traducción literal, palabra por palabra, 5) calco léxico, 6) transposición, modificando la categoría gramatical de la lengua origen, 7) modulación, alterando aspectos morfosintácticos de la lengua de origen, 8) adaptación mediante la sustitución de un elemento de la cultura origen por otro de la cultura receptora, y 9) paráfrasis o circunloquio. Esta variedad de estrategias revela la complejidad de esta traducción y las implicaciones que estas soluciones podían tener de cara a evitar la "confusión" y a asegurar la comprensión y arraigo del discurso doctrinal en el nuevo cristiano. Como señala Zamora (2012), elegir una u otra de estas posturas fue un tema recurrente que cada una de las órdenes religiosas tuvieron que plantearse. Esta problematización respondió más bien a una obsesión por la ortodoxia, como no podía ser de otra manera en unos siglos XVI y XVII sacudidos por la Reforma y la Contrarreforma. Es decir, sea como proceso de resemantización o de ampliación semántica, sería difícil -casi imposible- erradicar de los equivalentes esa carga anterior que precisamente los hacía "equivalentes", aunque desde planteamientos monoteístas no podía tolerarse ninguna ambigüedad ni ambivalencia que generase un tipo de sincretismo o hibridismo propio del pensamiento politeísta y henoteísta.

Esto se concreta en poder "nativizar", "naturalizar" lo que de por sí se veía conceptualmente como nuevo, susceptible de rechazarse como algo invasivo, intrusivo, en competencia con los sistemas religiosos preexistentes. Bien sabemos que esto acabó imponiendo una mistificación de la historia, una reinterpretación de la memoria que facilitara a los grupos conversores entender las nuevas realidades como objetos y episodios de su narrativa histórica, y a los grupos conversos reconocerse como parte de una agustiniana historia sagrada donde la intervención de la Divina Providencia se reconoce a través de episodios revestidos de señales que dibujan el triunfo del cristianismo, si no de un proto-cristianismo. Incluso se vio esta evangelización como parte de un movimiento ecuménico. Esta (re)cristianización se complementó con una demonización o satanización de las "idolatrías", una "conceptualización del mal como una amenaza entronizada en el otro" (Báez-Jorge 2013: 43), que debe entenderse como la integración del hecho religioso no conciliable con el mensaje evangélico como parte de lo anticristiano, como ya enunciaron los primeros evangelizadores (Olmos 1993), y como un temor a la desviación de sentido en la traducción y recepción que conllevara posicionar al neófito en la herejía.

Es importante señalar estos aspectos, pues nos ayudan a dibujar el horizonte y locus de enunciación de los traductores de la doctrina cristiana. Si la función de la lengua y su naturaleza atribuida por el traductor dependen del carácter del texto que se quiere traducir (Kelly 1979: 4), esta complejidad se amplía desde la muldimensionalidad que establecía Louis Kelly, y también desde una red cultural (inter-cultural) 
que hay que destejer (Berman 1984). Así, las preguntas básicas que según Antoine Berman (1984: 71) deben guiar el estudio sobre la historia de la teoría de la traducción - por qué traducir, cómo traducir y qué traducir-adquieren en el contexto de la evangelización un aspecto dialógico que implica más que una indagación de equivalencias, una conflictiva negociación lingüística de sentidos y significados. Si bien es cierto que a medida que aumentaba el dominio político y económico del mundo hispano se generaba un contexto cada vez más asimétrico y monológico, donde los referentes "mestizos" se iban imponiendo, se advierten soluciones y estrategias traductivas que abogan por un acercamiento intercultural, pero sin olvidar que en último término se aspiraba a imponer una univocidad en la semántica discursiva a partir del acto ilocutivo y performativo del ritual, además de la argumentación doctrinal y catecuménica.

\section{La traducción de las especies eucarísticas a la comunidad nahua}

El caso de la traducción al náhuatl de la eucaristía es el de una traducción que no surge como efecto de una curiosidad de un grupo que traduce a otro para conocerlo. Emerge más bien como una traducción para influir y transformar el sistema religioso del otro. Esto detonó un complejo proceso de inserción, proposición, apropiación y sustitución cultural que requirió conocer en profundidad las realidades que se quería transformar, y recurrir a aquellos elementos y recursos que pudieran facilitar reconocer como propio lo ajeno y como viejo lo novedoso, meta difícil cuando la lengua de traducción no es la lengua materna del traductor.

Esta dificultad surgió al buscar equivalente a elementos como pan y vino para conseguir trasladar el valor místico del rito y la posibilidad de implantar y establecer como propio en la comunidad conversa algo a todas luces exógeno. Las estrategias para "domesticar" elementos ajenos no dejarían también de recurrir -a ojos del nativo- al disfraz lingüístico y a la reinterpretación simbólica en su afán por lograr la aceptación de lo ajeno como algo familiar, ancestral o renovado, pues construir un signo bicultural implica una extensión semántica, no una resemantización. No es seguro que fuera ése el objetivo de los religiosos traductores, pero sí podría haber sido el de sus colaboradores nahuatlatos (cfr. Tavárez 2000: 28-29). Estos traductores, interesados en controlar el mundo de significados del otro, tratarían de introducir un signo monocultural bilingüe, más si cabe porque no era posible reconocer o aceptar ciertas "equivalencias" que deberían darse "siempre en una perfecta síntesis entre fe y cultura" (Bueno 2007: 37). Por tanto, traducir la eucaristía fue un proceso de transculturación, e incluso de inculturación si se ubica como parte de un proceso dialógico. Este carácter estaría acentuado si por parte del evangelizador y evangelizado hubo intentos por comprender el sentido simbólico-ritual de la misma, estableciendo su contenido nuclear y negociando su significación para representar un continuum cultural y lingüístico.

Sobre la traducción de las especies eucarísticas pareciera que algunos especialistas afirman que tales conceptos no se tradujeron simplemente por ser demasiado nuevos y sin equivalentes en la cultura meta. Incluso se afirma que se trataría de una transferencia cultural para la cual no era posible generar ninguna adaptación; como 
mucho expresarlo a modo de paráfrasis ${ }^{3}$. Como se verá a partir de un análisis descriptivo del caso, traducir las especies de la eucaristía al náhuatl implicó durante casi cuatrocientos años un diálogo que redujera la potencial double mistaken identification mediante un proceso de aculturación-inculturación. Este proceso de definición e inserción semántica a nivel lingüístico se expresaría a través de la extensión semántica, la acomodación lingüística y la adaptación léxica. Así, la generación de un signo bicultural podía al final considerarse un elemento completamente naturalizado $\mathrm{y}$, por tanto, un equivalente funcional para la transferencia traductiva. Para aclarar toda esta cuestión de modo más preciso conviene revisar qué asociaciones y criterios determinaron la conveniencia o no de ciertas equivalencias respecto a la liturgia y al mensaje evangélico.

\section{La presentación de los dones: el pan y el vino como alimento material}

En 1525 se instaló el primer Santo Sacramento en el Convento de San Francisco de México. Desde entonces, la eucaristía fue algo cotidiano en la vida de una neófita comunidad nahua cristiana a la cual habría que explicarle el sentido simbólico de la misa. Si bien inicialmente hubo controversia sobre si los nativos debían o no recibir la comunión (Motolinia 2001: 136; Mendieta 2002: 458-459), desde 1546 ya no hubo motivos para negársela, al menos a quien demostrara comportarse y prepararse como un buen cristiano y fuera capaz de entender la diferencia entre pan material y sacramental (Mendieta 2002: 459).

Podemos entender que entre 1530 y 1550 se hizo imperioso que los nahuas identificaran e introdujeran en su práctica ritual las dos especies eucarísticas, el pan y el vino, aunque, como se desprende de las doctrinas de la época (Córdoba 1550; Gante 1553), la misa se hacía en una sola especie (pan), pues entonces el vino y el cáliz eran elementos exclusivos para los clérigos (Basurko 2006: 299). Su introducción en el rito debía acompañarse del establecimiento de su valor simbólico y místico, labor complicada si quería hacerse desde la lengua náhuatl, pues estos dos alimentos se desconocían en Mesoamérica. Por tanto, hubo que determinar cuáles serían los referentes objetuales susceptibles de compararse con éstos y que tuvieran cualidades como para mostrarse como alegorías.

Para esto es oportuno revisar los corpus lexicográficos tempranos para ver si ya registran equivalentes para ambas especies. En la copia manuscrita del Dictionarium ex Hispaniensi in Latinum Sermonem de Antonio de Nebrija, que hacia 1540 sirvió de base para un inicial vocabulario trilingüe, hallamos un primer registro para el grupo del vino ${ }^{4}$ (1492: 156v). Éste evidencia lo difícil que fue completar los equivalentes por un aún impreciso conocimiento de la realidad nahua o la no existencia de tales conceptos desde el punto de vista emic, señalando vacíos léxi$\cos$ (Cuadro 1).

Así parecería desprenderse de la mención que hace Elena Irene Zamora sobre el uso en náhuatl de la palabra hostia (2012: 118); o de la mención al uso de tlateuchihuallaxcaltzintli por Susanne Klaus (Zwartjes 2016: 52). Evidentemente, estas menciones no responden más que a la identificación de usos parciales en una sola fuente.

4 El grupo del pan no aparece, pues en el folio 135r el copista se saltó dos páginas, pasando de la entrada "paloma macho desta especie" a la entrada "paz". 
Cuadro 1. Entradas trilingües del grupo vino

\begin{tabular}{lll}
\hline \multicolumn{1}{c}{ Castellano } & \multicolumn{1}{c}{ Latín } & \multicolumn{1}{c}{ Náhuatl } \\
\hline Uino generalmente. & Vinum- . temetum- $i$. & Vino \\
\hline Uino puro sin agua. & Merum- $i$. & Vino motquitieni \\
\hline Uino rebotado o desuanecido. & Vappa-ae & Tlaucxitilli vino \\
\hline Uino cozido. & Defrutum- $i$ & \\
\hline Uino bastardo & Vinum passum & \\
\hline Uino de mosto torcido & Vinum tortiuum & \\
\hline Uino aguapie & Lora- $[$ a]e. Vinum secundarium. \\
\hline Uino espesso de mucha hez & Rubellum-i. & Tlaaiotilli vino \\
\hline Uino de trigo de mançanas & Sicera-ae. & Vino tlachichiualli \\
\hline Uino aguado. & Vinum dilutum vel mixtum & \\
\hline Uino con especias & Myrrhyna-ae & Coztic vino \\
\hline Uino con miel & Mulsum-i. Oenomeli & Chichiltic vino \\
\hline Uino blanco & Amineum vinum & Totoloc milpa (sic) \\
\hline Uino tinto & Vinum rubeum &
\end{tabular}

Esta idea de registrar o, mejor dicho, de cubrir y completar el listado es un acercamiento inicial que ineludiblemente descubría que ambas lenguas mostraban mundos culturales y verbales diferentes. Esta distancia lingüística y cultural ya la señaló Nebrija cuando declaró la dificultad para encontrar equivalentes a todas las formas latinas y castellanas en su Dictionarium latino-hispanicum (1492), pues "Si quisieremos bolverlo en castellano: a penas lo podremos hazer en muchas palabras", y si acaso se creara una nueva palabra "seria la interpretación derecha e castellana: mas pocos entienden que cosa aquello sea" (Nebrija 1492: 3r-v). Esto tiene su implicación para traducir.

Podría pensarse que confeccionar un diccionario bilingüe bidireccional nacía de la creencia en que debe de haber una correspondencia palabra por palabra, pero como bien avisa Nebrija "no siempre dimos palabras castellanas a las latinas: e latinas a las castellanas" (1492: 3v), por tanto, y citando al De optimo genere oratorum de Cicerón, no se podía optar más que por una interpretación del sentido, sea como traducción aproximada, perifrástica o neológica. Igualmente se percibió en el caso del náhuatl y el castellano. Molina advierte en sus avisos de la necesidad de salvar los vacíos mediante neologismos lo que, como dijo Nebrija, tiene el riesgo de que el término propuesto no sea comprensible o familiar al no estar aún compartido, "y assi dezimos, Abaxador, aunque no se vsa en nuestro romance: por declarar lo que quiere dezir esta palabra, Tlatemouiani, la qual en buen romance, quiere decir, el que abaxa algo" (1571a: Aviso primero). Por lo mismo también registra aquellas palabras que los nahuas han generado espontáneamente con el contacto, pues "Las quales composiciones están tan vsadas que no las dicen de otra manera: y por esta razon, las deuemos tambien nosotros vsar de la misma manera que ellos las vsan" (1571b: Aviso nono). 
Cubrir vacíos léxicos supuso crear nuevos términos, modificar o ampliar significados y generar perífrasis a modo de definiciones explicativas per se, aprovechando las cualidades expresivas de la palabra-oración nahua. Se confiaba en la capacidad creativa de las lenguas vernáculas para crear palabras que permitieran trasladar nuevos sentidos. Así, para 1550 las cosas se habían en cierto modo normalizado, y lo más significativo, naturalizado. En el primer vocabulario castellano-mexicano impreso (Molina 1555), el pan y el vino ya fueron identificados con elementos autóctonos. Dentro del grupo del pan (Cuadro 2) se optó por el término tlaxcalli, la tortilla cocida de maíz, que expresaba la idea del pan como alimento cotidiano y básico, hecho de harina y acompañante de las comidas. Se obvió que la sustancia fuera maíz y no trigo, aunque se aprovechó la cualidad aglutinante del náhuatl para introducir la sustancia foránea como sustantivo prefijado. Así el pan de harina sería la 'tortilla de Castilla' (Castillantlaxcalli) o la 'tortilla de trigo' (trigotlaxcalli).

Cuadro 2. Grupo del pan en los vocabularios de Alonso de Molina

\begin{tabular}{l|l}
\hline \multicolumn{1}{c|}{ Vocabulario castellano-mexicano 1555 } & \multicolumn{1}{|c}{ Vocabulario castellano-mexicano 1571} \\
\hline Pan generalmente. Tlaxcalli. & Pan generalmente. Tlaxcalli. \\
Pan de ceuada. Ceuadatlaxcalli. & Pan de ceuada. Ceuadatlaxcalli. \\
Pan de trigo. Castillantlaxcalli. Trigotlaxcalli. & Pan cozido debaxo la ceniza. Tlecoyotl. \\
Pan cozido debaxo la ceniza. Tlecoyotl. & Pan cozido en horno. Texcalco ycucic tlax- \\
Pan cozido en horno. Texcalco ycueic tlax- & calli. \\
calli. & Pan de maiz cozido en ollas. Tamalli. \\
Pan de acemite. Tlatzetzeliuhcatlaxcalli & Pan de acemite. Tlatzetzeliuhcatlaxcalli. \\
\hline
\end{tabular}

En la edición del vocabulario de 1571 (Molina 1571a) se confirma la tendencia a imponer como referente la realidad mesoamericana sobre la europea (ver Cuadro 2). La entrada de "pan de trigo" se eliminó e incorporó la de "pan de maiz cozido en ollas", y a nivel pragmático y coloquial se incluyó la palabra tlaxcalli como sinónimo de pan, pues comparte su concepto como alimento procesado, común y necesario. Respecto al vino (Cuadro 3) en el vocabulario de 1571 se repiten las mismas entradas que en el de 1555, aunque frente a 1540 hubo muchos cambios. Si en la versión trilingüe del Dictionarium ex Hispaniensi se partió sólo del concepto castellano y latino de vino, trasladando la palabra vino al náhuatl, después se pasó a una estrategia comprensiva que determinó abrirse a elementos locales equiparables. Aquí se tendió a adoptar un equivalente nativo para denominar una bebida alcohólica, el pulque (octli). Pero no nos llevemos a engaño. El caso específico del "vino tinto", no se nombró como variación de octli, sino de vino (tlapalvino, chichiltic vino).

Por tanto, octli no reemplaza a la palabra vino, sino que convive con ella. Si octli se considera un genérico en Mesoamérica, como el vino de estas tierras, e incluso un sinónimo para generar paráfrasis con las que el nativo pueda explicarse qué es vino, nos damos cuenta de que por alguna razón no es un sustituto general de la palabra vino empleada por los españoles. "Vino" como palabra náhuatl identifica al vino puro o aguado, al licor de frutas (extranjeras) y al vino tinto, al pulque no mesoamericano. Esto es comprensible pues ambos contrastan en su relieve de transparencia, textura, color y graduación, además de que el pulque no es procesado del jugo de un fruto, sino de una planta. 
Cuadro 3. Grupo del vino en los vocabularios de Alonso de Molina

\begin{tabular}{|c|c|}
\hline Vocabulario castellano-mexicano 1555 & Vocabulario castellano-mexicano 1571 \\
\hline Vino & eralmente. Octli. \\
\hline $\begin{array}{l}\text { Vino puro sin agua. Motquiticauino. Amo } \\
\text { ayo uino. }\end{array}$ & $\begin{array}{l}\text { Vino puro sin agua. Motquiticauino. Amo } \\
\text { ayo uino. }\end{array}$ \\
\hline $\begin{array}{l}\text { Vino rebotado o desuanecido. Amo chicauac } \\
\text { octli. }\end{array}$ & $\begin{array}{l}\text { Vino rebotado o desuanecido. Amo chicauac } \\
\text { octli. }\end{array}$ \\
\hline Vino cozido. Ocpauaxtli. Tlatexcalhuilli. & Vino cozido. Ocpauaxtli. Tlatexcalhuilli. \\
\hline Vino agua pie. Tlaixpac octli. Ocpatzquitl. & Vino agua pie. Tlaixpac octli. Ocpatzquitl. \\
\hline Vino e & Vino \\
\hline z. Tlaoloctli. Teuhoctli. & Vino de trigo o mayz. Tlaoloctli. Teuhoctli. \\
\hline Vino de mançanas. Castillatexocooctli. & Vino de mançanas. Castillatexocooctli. \\
\hline $\begin{array}{l}\text { Manç } \\
\text { Vino }\end{array}$ & $\begin{array}{l}\text { Mançanaoctli. } \\
\text { Vino de miel. } A\end{array}$ \\
\hline Vino de ciruelas o de limones. Xocooctli. & Vino de ciruelas o de limones. Xocooctli. \\
\hline Xocovino. & Xocovino. \\
\hline Matzaoctli. & Vino de piñas. Matzaoctli. \\
\hline choctli. & Nochoctli. \\
\hline Vinc & s. Capuloctli. \\
\hline Tlaayotilli vino. & Vino aguado. Tlaayotilli vino. Ayo vino. \\
\hline Tlachiualoctli. & n miel. Tlachiualoctli. \\
\hline Vinc & Vino blanco. Yztac octli. \\
\hline octli. & Vino haloque. Cuztic octli. \\
\hline Vino tinto. Tlapalvino. Chichiltic vino. & Vino tinto. Tlapalvino. Chichiltic vino. \\
\hline
\end{tabular}

Esto explicaría por qué en textos religiosos tempranos como la Doctrina Christiana traducida al náhuatl de Pedro de Córdoba (1550), el Tratado de Andrés de Olmos (1553) y la Doctrina Christiana de Pedro de Gante (1553) se nombraran las especies exclusivamente como tlaxcalli y vino, aunque en el caso de Córdoba la traducción enfatice su origen (castillan tlaxcalli, castillan vino) por sujetarse a una traducción "sentencia por sentencia". Así también, las primeras versiones en náhuatl del Pater Noster (Córdoba 1550; Gante 1553: 101v-102r), tradujeron la expresión "panem nostrum quotidianum" respectivamente como "in totlaxcal imomoztlae" e "in totlaxcal momoztlaye", forma reproducida de modo prácticamente invariable en las doctrinas y catecismos publicados en Nueva España y México. Así se generó un signo bicultural, una double mistaken identification, que podía entenderse como tortilla/pan, pero que establecía una categoría intercultural que nombraba al alimento cotidiano, compartido y proporcionado por la gracia divina.

A mediados del siglo XVI estos elementos, si no se tenían, al menos eran familiares para la comunidad nahua y la élite indígena, hasta poder afirmar Motolinia que "los indios todos se mueren por nuestro vino" (2001: 102). Si al incremento de toneles de vino importados, más para su uso litúrgico, se le añade que al menos a partir de1534 el trigo se iría sembrando de modo más extensivo en Texcoco y Puebla, queda claro que el vino y el pan de trigo ampliarían su presencia en la república de indios, al menos como producto para el pago de tributo o de los diezmos. Ya para el siglo XVII el uso figurado o extensivo de la palabra tlaxcalli como signo bicultural empezó a considerarse limitado o a ser limitado de nuevo al pan de maíz por los nahuas. Esto se infiere porque, frente a un sentido generalizado, en las traduccio- 
nes se va requiriendo cierta especificación aludiendo a características de la materia. Por ejemplo, algunos sermones de 1559 mencionan al pan consagrado como iztac tlaxcaltzintli (pan blanco) (Tavárez 2000: 24), término que perdurará junto con vino hasta fines del siglo XIX incluso en representaciones teatrales (McAfee 1953: 249). Así, Martín de León, al hablar de la comunión, usa chipahuac tlaxcalli (pan blanco, limpio) y vino como especies (1611: 130-132).

La precisión de la sustancia como harina de trigo empezó a recalcarse, aunque sin aún diferenciarla nominalmente. Pero a partir de la mitad del siglo XVIII en náhuatl se popularizó un neologismo que diferencia más claramente el pan de maíz del pan de trigo. Junto a tlaxcalli, va a hacer acto de presencia en las nuevas traducciones el préstamo pantzin, aunque no por ello deba considerarse una transferencia, pues previamente pasó por su naturalización morfológica. Es evidente que esto representó un punto de quiebre, un cambio en los criterios de traducción y un reflejo de una hegemonía cultural donde las relaciones se hacen más asimétricas a nivel económico y productivo.

Esta necesidad de los nahuas de diferenciar dos tipos de panes sugiere un mejor conocimiento de las naturalezas culturales y un reconocimiento en esa diferencia de un valor social y funcional de una realidad sobre otra. Así, la semántica cultural recalcaba que cada palabra contenía significados socialmente productivos como etiquetas que identificaban a cada pan con orígenes y pertenencias étnicas diferenciadas. Curiosamente, aunque ambos elementos fueran siendo más familiares, era más necesario por tal razón diferenciarlos, y los traductores aprovecharon para, ahora ya sí, recalcar que el pan a consagrar debía ser de trigo. En cierto modo es parecido a lo que pasó con el vino. Aunque fuera un concepto más familiar, su denominación como huino sería un neologismo con el que los nahuas recalcarían la foraneidad de la bebida, lo que explica por qué octli no fue reemplazado por huino y mantendría su significación primigenia, aunque los nahuas extendieron su uso a cualquier aguardiente. Serían pues distintivos étnicos de consumo. Así la república de indios (tortilla-pulque) y la república de españoles (pan-vino) estarían representadas por una sinécdoque alimentaria.

No obstante, esto no representó sustituir tlaxcalli por pantzin en doctrinas ni oraciones. Más bien implicó un doblete, siendo un elemento que especificaba el género de tlaxcalli como a su vez lo hiciera Caxtillantlaxcalli. El signo 'tortilla/pan' (tlaxcalli) se reemplazaría por la paráfrasis 'tortilla, pan'. Así, el jesuita Ignacio de Paredes empleó las expresiones "oquimotenquixtili in Teotlâtolli in ipan Tlaxcalli, Pantzin, ihuan ipan Tlailli Vino" (1758: 195) y "yê oquimotzonquixtili in Teotlâtolli, in ipan in Caxtillantlaxcalli, Pantzin (...) ihuan in ipan Caxtillantlailli, Vino" (1758: 99), con lo que reconoce pantzin como palabra corriente para identificar el pan material a consagrar, definiéndolo como 'tortilla' (tlaxcalli) o 'tortilla de Castilla' (Caxtillantlaxcalli), en un sentido de alimento, mientras que vino se incorporó como tal y se aclaró en un doblete que es bebida (tlailli, Caxtillantlailli). Aunque aún en algunos textos se usó con un sentido purista tlaxcaltzintli (tlateochihual tlaxcaltzintli), como por Pedro J. Gambino, el traductor del Piadoso Devocionario en Honor del Sagrado Corazón (Almeida 1839), durante el siglo XIX se establecerá una preferencia por pantzin. Así se menciona "in pantzi ihuan vino quimoteochihuilia in teopixcatzintli" en el libro doctrinal Explicación clara y sucinta de los principales misterios de nuestra santa fé (Anónimo 1835: 338), o en una oración fechada en 1832 se declara, a propósito de diferenciar el pan material del eucarístico, “(...) Amo pantzi manel nezi 
/ Tlen nepa ticmoceliliz (...)" (Vázquez 1860: 33). Igualmente, al hablar del efecto transubstanciador de la plegaría eucarística sobre las especies se usa pantzin y vino (Anónimo 1840: 14).

¿Supuso por tanto la irrupción de pantzin una propuesta de "modernización" en el lenguaje litúrgico nahua? Al margen de evidenciar la presión colonial del mundo hispano-mestizo, era una opción, si acaso, que quería ser menos ambivalente. Por una parte, tlaxcalli se mantuvo por el carácter formulario y canónico del padrenuestro, donde se usó siempre; pero también para fines del siglo XIX se seguía usando para hablar del pan material como en la traducción de Miguel Trinidad Palma (1886: 22) del Catecismo de Ripalda. Así, se usaría vino, tlaxcalli o pantzin en la identificación de las especies como alimento básico terrenal (algunos textos lo nombran totlalnacayoh), permitiendo explicar y hacer entender que, igual que el cuerpo tiene hambre, el espíritu también, y este alimento sólo lo proporciona la Iglesia, por lo que será la base para traducir las especies como alimento espiritual.

\section{La comunión de dos especies: el pan y el vino como alimento espiritual}

Si pareció sencillo lograr una traducción transcultural de las especies, dar a entender que éstas se transformaban en alimento espiritual ya era otra cosa. Este aspecto central no ya de la celebración de la misa, sino de la participación del sacramento de la comunión, requería familiarizarse con varios conceptos clave de la teología católica. Primero había que identificar si existía en las creencias indígenas un "alimento para los dioses", y si éste se compartía con los celebrantes ceremoniales en un symposion. También, si quien comía ese alimento se alimentaba de ese mismo dios y por tanto nutría su alma hasta el punto de entrar en comunión con la divinidad. Así planteado, casi lo que menos importó fue entender el aspecto simbólico subyacente de la conmemoración de la muerte de Jesucristo, sino comprender que en el pan y vino eucarístico se hallaba la presencia real de su cuerpo y su sangre, en tanto que su muerte suponía su sacrificio ("hostia") para poder ser alimento redentor del alma.

Estos conceptos de comunión y epifanía divina, paradójicamente, sí fueron detectados como conceptos preexistentes a la llegada del cristianismo, al menos en la principal de las religiones, el culto a Huitzilopochtli. Ya el franciscano Toribio de Benavente advirtió que en el mes de panquetzaliztli se hacía presentación y alzamiento ante el altar de los corazones de hombres-dioses sacrificados, que daban a probar a la imagen del dios y eran consumidos sus cuerpos por los viejos sacerdotes y sus oferentes (Motolinia 2001: 42). También señaló que se celebraba con carácter incruento una comunión donde los fieles comían el cuerpo de Huitzilopochtli para participar de su fortuna. Bernardino de Sahagún (2006: 152) especifica que, para este dios y para el dios Tlacauepancuexcotzin, se hacían sus imágenes a tamaño natural de tzoalli, que se subían a lo alto del templo para después bajar "la estatua de Huitzilopochtli cautiva, que era de masa, y llevábanla para sus casas y hacían convite con ella a sus parientes y a todos los de su barrio" (2006: 141). Este descendimiento y fraccionamiento, como sacrificio incruento, fue inmediatamente identificado con la misa y la comunión e incluso el tzoalli como un alimento para el espíritu, toyollia ytlaqual como "nahuatlizaron" metafóricamente tal concepto los evangelizadores 
(Olko y Madajczak 2019: 80), amén del sacrificio pascual como señala Diego Durán ${ }^{5}$ (2002: 40,43-44), e incluso José de Acosta llega a identificarlo con el mismo Corpus Christi (2003: 347-350).

Esta práctica facilitó a los nahuas entender el significado de la eucaristía como como teteo imixiptla, un sustituto o representación de los dioses (Olko y Madajczak 2019: 79), pero este descubrimiento, por otro lado, generó entre los religiosos una gran desconfianza como para tomarlo de referente. Se consideraba una "misa negra", es decir una parodia o una corrupción del sacramento de la eucaristía, y por tanto sus elementos no podían ser "inculturables". En términos traductivos se diría que lo juzgaban un "falso amigo" que operaría como disfraz lingüístico, siendo más prudente no traducir desde este elemento el alimento sacramental. Si se añade que en el siglo XVI se remarcan ciertos dogmas y ritos para reafirmar la identidad católica frente a los movimientos reformistas, y anteriormente ante las iglesias cristianas orientales (transubstanciación, pan ácimo, comunión en una especie, en la boca y de rodillas, ayuno eucarístico), no se debía hacer nada que se saliera de la ortodoxia. Hubo que acudir a la perífrasis explicativa (Córdoba 1550) y sondear si en esta transformación de los alimentos no sería conveniente excluir aquellos términos que generaran ambigüedad o ambivalencia, y si fuera conveniente, remarcarlo con la transferencia de términos de origen latino o castellano, o usar algún recurso lingüístico de la lengua náhuatl para expresar el cambio de naturaleza en la sustancia del alimento.

En este punto, el trabajo gramatical y lexicográfico entre los frailes gramáticos e indios latinos debe apreciarse como un proceso de traducción transcultural, pero con el fin de lograr una transposición y dominación traductiva. No se trató de identificar convergencias semánticas o vacíos conceptuales, sino de apropiarse de los significados y rellenarlos con significados propios que conformaran sus propios teteo imixiptlahuan, es decir, aspectos que fueran "nomished by the Eucharist, wich has been projected onto a Nahua cultural practice" (Olko y Madajczak 2019: 80). Se quiso controlar por completo los sentidos denotados y connotados del lenguaje litúrgico, con una finalidad evangélica y a fin de eliminar cualquier rastro de las religiones previas. No se pretendió generar un vocabulario bidireccional, sino un nuevo vocabulario compartido con la comunidad cristiana pero que se sintiera propio de los nahuas. Esto se advierte en el interés por recoger todos los aspectos ceremoniales y creenciales de los naturales y ver desde donde asentar estos nuevos principios, cuidándose de no perpetuar aquellos que fueran demasiado "nativos", es decir, no expropiables. Por tanto, se dispuso de suficiente información para entender si estos alimentos representaban perfectamente la idea de los alimentos esenciales y "transustanciables", y si podían considerarse alimentos ceremoniales, es decir, si se concebían como alimentos del cuerpo y del espíritu, de los cuales se alimentan los hombres, los ángeles y Dios hijo, las especies que participan de los sacramentos; y algo muy importante, no estaban vinculados con sacrificios cruentos. A tal respecto, la información recopilada por Sahagún $(2006: 37,39,142)$ de algunas celebraciones asociadas a ciertos alimentos, cuya variedad, preparación, presentación y consumo

Diego Durán manipula algunos aspectos en su descripción, quizás por su insistencia en ver en los antiguos pueblos de México a las tribus perdidas de Israel (2002: 53-54). Así aseguró que la fiesta de panquetzaliztli coincidía con la Pascua hacia el mes de abril, cuando más bien comienza en la segunda quincena de noviembre. Quizás en cierto modo estuviera confundiéndola con las fiestas de tlacaxipehualiztli o de tozoztontli, donde se sacrificaba a Xipe Totec y a Tlaloc respectivamente. 
describe al detalle (Cuadro 4), es clave para entender la variedad de posibilidades traductivas.

Cuadro 4. Alimentos rituales de algunas ceremonias religiosas

\begin{tabular}{llll}
\hline \multirow{2}{*}{ Fiesta } & \multicolumn{1}{c}{ Comida } & \multicolumn{1}{c}{$\begin{array}{c}\text { Traducción según la } \\
\text { fuente }\end{array}$} & \multicolumn{1}{c}{ Identificación ritual } \\
\hline \multirow{4}{*}{ Xochilhuitl } & Tamalli & Pan redondo de maíz & Pan de ayuno \\
\cline { 2 - 4 } & Tzoalli & $\begin{array}{l}\text { Pastel o torta de bledos } \\
\text { [amaranto] }\end{array}$ & Ofrenda/comida \\
\cline { 2 - 4 } & Xonecuilli & pan de manera de rayo & Ofrenda/comida \\
\cline { 2 - 4 } & Yotlaxcalli & $\begin{array}{l}\text { Pan hecho de manera de } \\
\text { mariposa [maíz] }\end{array}$ & Pan ácimo \\
\cline { 2 - 4 } & tlacuilolatolli & Atole pinto & Ofrenda/bebida \\
\hline Atamalcualiztli & atamalli & Tamal hecho sin sal & Pan de ayuno y ácimo \\
\hline \multirow{3}{*}{ Izcalli } & quiltamalli & $\begin{array}{l}\text { Pastelejo hecho de bledos } \\
\text { [amaranto }]\end{array}$ & Ofrenda \\
\cline { 2 - 4 } & octli & pulque & Ofrenda/bebida \\
\hline
\end{tabular}

Aquí detectamos aquello que interesó resaltar e identificar como equivalencia ritual y simbólica: comprobar que hay "pan de ayuno" y "pan ácimo", que estas realidades son tanto alimento de hombres como de dioses, y que además se preparan y comen en ceremonias concretas. Así, en el caso del yotlaxcalli se advirtió que "el maíz de que se hacía el pan que comían no se cocía con cal, antes de molerlo, que esto es como hormentar, sino molían el maíz seco y de aquella harina hacían pan y cocíanlo en el comal, y no comían chilli ni otra cosa con ello" (Sahagún 2006: 39). Como alimento de la divinidad se destaca que el atamalli se consumía y se ofrecía para alimento de los dioses (2006: 142). Igualmente, el quiltamalli no podía comerse sin antes haberlos ofrecido al fuego (2006: 37). Diego Durán (2002: 34-35) también nos recuerda que estos alimentos, como ofrenda, son alimento para los dioses, como los macpaltlaxcalli xopaltlaxcalli, cocoltlaxcalli que le preparaban y le servían a Huitzilopochtli. Esto les permitió darse cuenta de qué modos de preparación se adecuaban más a su idea de pan ritual, sea para identificar o para explicar cuál es el pan que comió Jesús en vida y qué pan se transformó en su cuerpo.

Apreciamos tres tipos de preparaciones básicas susceptibles para nombrar al pan de la misa: el tamalli, el tlaxcalli, y el tzoalli. Estas opciones cargadas de sentidos litúrgicos preestablecidos los convertían en potenciales "equivalentes" o "sustitutos". El tzoalli o tzohualli era un tipo de pan que se vería más bien como bollo o dulce festivo, a modo de hornazo, recubierto de miel y amaranto. Esta sustancia fue desechada al no ser alimento cotidiano ni una ofrenda habitual para los dioses y, en especial, por ser para celebrar la comunión con Huitzilopochtli. Por otro lado, el tamalli se concibió por su preparación como pan ácimo y de ayuno. La textura de su masa podía asociarse con la carne, pero no era fácil asimilarlo con el pan cotidiano que comió Cristo en la última cena. Por esto, el pan litúrgico se nombró tlaxcalli, 
pues ofrecía la seguridad de ser una especie que funciona (se entiende) como alimento de hombres, alimento divino y ofrenda a un dios. Así se convirtió en alimento ceremonial, siempre que se operara una transformación gracias a la presentación y plegarias rituales, y su elaboración coincidiera con el del pan ácimo católico y se asemejase a la forma de la oblea. Por ello, el que se identifiquen ofrendas de tlaxcalli como alimento ritual ácimo y con previo ayuno es una cualidad que no se les escapó a los religiosos para verlo como un término polifuncional (un signo bicultural) sobre el que proyectar la semántica profana (alimento del cuerpo) y religiosa (alimento del alma) del pan de la liturgia católica, y así lo reconocerían también los nahuas. ¿Pero cómo se expresaría la diferencia entre pan material y pan espiritual? ¿Cómo se daría a entender que, en la consagración del pan, éste se transforma en "hostia", es decir, ya no es pan, sino el cuerpo de Cristo?

En algunos casos se tendió a emplear el préstamo ostia, oztia, hostia o santa hostia (Paredes 1758: 99; Anónimo 1835: 72-74). Sin embargo, el uso de esta palabra y de santissimo sacramento se vería como un término propio de un lenguaje litúrgico oscuro (nahuallahtolli), es decir, casi se tomaría como un nombre propio que reforzaría la devoción y piedad eucarística, siendo frecuentemente mencionado en esta forma (santisimo sacranmeto, sanctisimo sacramento) durante el siglo XVI en los testamentos nahuas (Rojas Rabiela et al. 1999). También lo vemos así empleado en las doctrinas y confesionarios durante largo tiempo (Velásquez de Cárdenas 1761: 45-46), aunque en una etapa tan tardía como el siglo XIX se quiso expresar en algunos textos de forma naturalizada, fuera de modo híbrido como teoyotica Sacramento (Almeida 1839: 51), o mediante perífrasis como teoyotica teyectililocatzintli (Ángeles 1883: 11), donde se recuperó de modo reverencial un término ya acuñado por Paredes (1758: 243). Pero el término que se popularizó para el pan consagrado, aprovechando los recursos lingüísticos del propio náhuatl, fue una variación de tlaxcalli. Ya para los años de 1550 Pedro de Gante naturalizó el término hostia con la forma tlaxcaltzintli, creando un uso oposicional entre tlaxcalli (pan cotidiano) y tlaxcaltzintli (pan celestial) al explicar el padrenuestro: "Ca quitoznequi totlaxcal momoztlae totech monequi in axcan ma xitechmomaquili. (...) Ma mopaltzinco xitechmomaquili yn ilhuicac tlaxcaltzintli, yn intlaxcal in angelome. (...) ca itlaqual in taniman yn toyollia: (...)" (Gante 1553: 19r). Este detalle es interesante, pues en la traducción de la doctrina de Córdoba (1550) no se genera dicha variación, remitiendo el uso del sufijo reverencial -tzin solo a la presencia transustanciada como itlaçonacayotcin en el caso del pan, y como itlaçoyezçotcin el vino. Así se estableció una diferencia relevante con la tortilla común, pero en sí no se trató de un neologismo. Ya en los Primeros memoriales Sahagún identificó el término tlaxcaltzintli como parte del registro nahuallahtolli al tratar sobre ritos y sacrificios, y consigna de boca de los ancianos que como ofrendas se presentaban tlaxcaltzintli tepitoton (pequeñas tortillas reverenciadas) (1558: 254v)

Esta solución, desde un comienzo, era fácil de entender y usar por la comunidad nahua cristiana. Así tuvo mucha popularidad, pues, aunque no volviera a aparecer en catecismos y doctrinas del siglo XVI que optaron más por los mencionados présta$\operatorname{mos}^{6}$, en las del siglo XVII se hace ya frecuente su inclusión en sermones para hablar del Corpus Christi y la comunión (Mijangos 1607: 337-338; 1624: Primera parte;

Así se corrobora en los vocabularios de Molina, cuyas ediciones establecen para hostia el equivalente de ostia, y que incluyen la entrada "ostiario de ostias. ostiacalli" (Molina 1555: 86r). 
León 1611: 128r). Si en 1571 se le decía icelilocatzin Santissimo Sacramento (Molina 1571a), ahora se le nombraba icelilocatzin in mahuiztlaxcaltzintli o yn icelilocatzin ynin ilhuicac tlaxcaltzintli (León 1611: 128v). Igualmente, en obras de teatro con tipo litúrgico y popular desde fines del siglo XVI hasta el siglo XVIII encontramos tlaxcaltzintli, Caxtillan tlaxcaltzintli y teoyotica tlaxcaltzintli para hablar de la hostia (Lockhart 1991: 71-72; Sell y Burkhart 2012: 198).

Puede concluirse que, a principios del siglo XVII, a la distinción entre tlaxcalli y ostia se suma la de tlaxcalli y tlaxcaltzintli $i^{7}$ para nombrar la sagrada forma. Así el uso del sufijo - tzin $^{8}$ que en origen expresa la devoción ceremonial, con la cristianización trata de representar una diferencia de naturaleza pero no de sustancia ${ }^{9}$, aspecto importante a la hora de explicar la transubstanciación, pues la presencia de la divinidad justificaría el uso devocional de -tzin, en cuyo caso se entiende tal respeto y veneración, se justifica en el momento que se transforma en el cuerpo de Cristo (inacayotzin, 'su carne', y en el siglo XIX, itlacayotzin, 'su cuerpo') mostrándose no tanto como un sacrifico si no como un autosacrificio. De este modo esta teofagia ritual no sería susceptible de confundirse con las creencias prehispánicas al respecto (aunque en sí esto fuera así) al no mostrarse como un sacrificio cruento ${ }^{10}$. Por todo ello, tlaxcalli-tlaxcaltzintli remitía a las cualidades que se necesitaban para incorporar todos los sentidos del pan consagrable, físico, social y divino. Al respecto, desde el siglo XVIII cuando se emplea pantzin en combinación o sustitución de tlaxcalli, al tener que referirse a la hostia se usó hostia, por lo que el uso de -tzin con pan no refleja el proceso de transubstanciación ni el tamaño. Su aparición como forma lexicalizada no solo identifica el pan de harina, sino que evita la ambigüedad de la palabra con otros elementos de la lengua (pan).

En lo referente al vino y a su consagración, su transformación en la sangre de Cristo (iezzotzin), vimos que su concepto, relieve y sustancia no permitía naturalizarlo como una extensión semántica de octli. No obstante, había otras bebidas rituales (ver Cuadro 4) que podrían haberse adoptado: el chilmole (chilmolli), el

Podemos encontrar ilhuicactlaxcaltzintli (pan del cielo), yoliliztlaxcaltzintli (pan de vida), yolcatlaxcaltzintli (pan vivo), tlaçotlaxcaltzintli (pan amado) y mahuiztlaxcaltzintli (pan admirado) (Mijangos 1624), necuiltonoliztlaxcaltzintli (venerado pan de gozo) (Paredes 1758: 156-157).

8 Se podría pensar que el sufijo - tzin también se refiere a su tamaño si se piensa que expresa un sentido diminutivo. Teniendo en cuenta que desde el siglo XII la hostia tenía un tamaño que oscilaba entre 4 y $7 \mathrm{~cm}$ de diámetro, tamaño inferior al de una tortilla de mano (en torno a $15 \mathrm{~cm}$ ), podría percibirse la oblea como una tortillita. Sin embargo, este uso diminutivo de -tzin es más reciente, expresando aquí sólo reverencia, afecto o compasión (Sullivan 1998: 40), pues a tal efecto se usaban otros sufijos como -ton o -pil. Esto justifica el uso de tepiton en las anotaciones citadas de Sahagún para expresar el pequeño tamaño de un pan ceremonial, o por Paredes el uso de tlaxcaltontli (1759: LVII) para hablar de un pan ínfimo.

9 Llama la atención que no se propusiera para los textos canónicos una forma teotlaxcalli, más coherente con otras innovaciones en el lenguaje cristiano (teotlahtolli, teoyotl, teopixqui). De acuerdo con Tavárez (2000: 24), está forma llegó a emplearse en algunos sermones en la segunda mitad del siglo XVI, y tuvo algunas opiniones a su favor (Tavárez 2000: 42). Sin embargo, su uso fue siempre cuestionado por las autoridades religiosas, lo que puede deberse a que, de usarse así, se habría concebido que la tortilla/pan tenía una cualidad o esencia divina per se, lo que sería un error doctrinal, además de haberse relacionado con el consumo de otros elementos también reconocidos como dioses (teonacatl, teooctli, ololiuhqui) y asociados a ceremonias prehispánicas consideradas idolátricas o demoniacas.

10 Recordemos que hostia es la palabra latina para designar a la víctima de un sacrificio menor que en la liturgia romana adquiere un sentido sustitutorio al remitir al sacrificio del cordero pascual de los hebreos, hecho que se considera representado en la crucifixión de Jesús como inmolación del primogénito en un doble carácter de sacrificio sustitutorio. 
atole (atolli) y el cacao (cacahuaatl). Algunas de estas bebidas por su color o textura, como el vino eucarístico, remitían a la sangre: el chilmole era una salsa roja y el tlacuilolatolli un atole pinto (Sahagún 2006: 38-39). El cacahuaatl, bebida de cacao ofrecida a algunos dioses menores (2006: 144) también se nombraba como yollotl, eztli, "corazón, sangre" (Sullivan 1998: 357), lo que expresa su uso ritual y metafórico, servidos en un cuauhxicalli que, a modo de cáliz, recogía la sangre y el corazón del sacrificado.

Incluso en algunas festividades su uso restringido se hacía extensivo, pudiendo interpretarse como fructus. Así ocurría con el matlaoctli (pulque azul) en la celebración de panquetzaliztli, cuando, tras los sacrificios humanos, iban a sus casas a beberlo "los viejos y viejas, y los casados y los principales" (Sahagún 2006: 142). La idea de una bebida espirituosa de consumo general y ceremonial se ajustaba así más al pulque. Aunque el consumo de esta bebida estaba regulado y prescrito a los ancianos, en el espacio ritual su consumo se hacía general, sin limitarse por razón de edad, género o estamento. Así, en la fiesta de pillahuano incluso los niños y niñas bebían pulque (2006: 38).

No obstante, el pulque, aunque pudiera colorearse para la misa, presenta características que no permitían su inculturación. Había cuestiones religiosas que no hacían aconsejable usar octli para nombrar al vino consagrado, ni siquiera mediante perífrasis como *tliltic octli o * chichiltic octli, aunque al vino blanco se le llamase iztac octli (cfr. Lockhart 1999). El problema es que el pulque para los nahuas no sólo se asociaba con la diosa Mayahuel y el dios Ometochtli, si no que se consideraba un dios. Además, la presencia ceremonial del pulque tenía un carácter orgiástico al permitir embriagarse como parte de la celebración, algo reprimido por los religiosos. La cuestión es que las especies son sustancias que encarnarán a la divinidad para permitir la comunión con el cuerpo místico de Cristo, pero no son (y no deben ser) formas que despierten devoción hacia sí mismas sin haber pasado antes por el acto de la consagración. Por tanto, se va a mantener el mismo término (vino, huino) para nombrar al vino consagrado, aunque también se usó con un carácter metonímico la palabra caliz. Así, las especies consagradas se nombraron en algún caso como oztia, caliz (Velásquez de Cárdenas 1761: 45-46), o santa hostia, santo caliz (Paredes 1758: 195) al revelarse como contenedores de Jesucristo en la tierra (como antes se había usado el cuauhxicalli). Pero lo cierto es la propia mención de iezzotzin le confería un sentido restringido, pues como especie no era un alimento cotidiano entre los nahuas, e incluso, por reservarse al sacerdote, no estuvo muy presente al comulgar salvo en la contemplación del cáliz. Así, parecía que en su asociación con el clérigo y en su propia naturaleza residía su especificidad como fructus divino.

Este ajuste terminológico, lexicográfico, semántico y semiótico de categorías supuso un esfuerzo de comprensión y planificación lingüística que trató de evitar la double mistaken identification en el fiel católico que aún sintiera que en la nueva religión y sus nuevos discursos pervivían antiguas creencias y ritos mediante el empleo de la extensión semántica (tlaxcalli), de la analogía (huino) o de la modulación (pantzin). Si bien los religiosos creían que estas soluciones traductivas ayudaban a evangelizar, a transculturizar sus creencias religiosas de modo naturalizador, e incluso a inculturizar algunos elementos conciliables o instrumentalizables a partir de la resemantización, su uso respondía más bien a demostrar y aprovechar la existencia entre los naturales de la piedad, la devoción, la sumisión y, en definitiva, la religiosidad emocional y racional, y no tanto a ver en ello una homologación de sus creencias 
previas con el cristianismo. A tal tenor no podemos omitir lo que nos recuerda Xabier Basurko: "la Iglesia tiene poder para mudar en la administración de los sacramentos, salvada la sustancia de ellos, aquello que, según la variedad de las circunstancias, tiempos y lugares, juzga más conveniente a la utilidad de aquellos que los reciben" (2006: 319).

\section{Conclusiones}

Entre los siglos XVI y XIX acontece todo un esfuerzo traductivo concretado en propuestas que contribuyen a formalizar un lenguaje litúrgico y un marcador semántico de la comunidad católica nahua. Esto supuso desarrollar los criterios de traducción sensum ad senso, y por tanto la traducción misional se desmarcó en algún caso de la supuesta fidelidad a los textos religiosos. Así se hacen eco de las mismas tendencias que se defendían entre los humanistas, pero también entre los reformadores religiosos. Esto creó una innovación o prevalencia de los aspectos comprensivos y comunicativos, transculturadores e inculturadores, de la traducción como herramienta aplicada a la conversión, que también se muestra en la defensa de una evangelización en las lenguas vernáculas. Esto se aprecia en el uso de la adaptación y la extensión semántica, lo que generó los signos biculturales tlaxcalli (tortilla/pan), huino (aguardiente/vino) y pantzin (pan español/pan) a través de procesos de apropiación y modulación por los nahuas que, en todo caso, sirvieron para identificar a las especies eucarísticas.

Este ajuste de mundos verbales y conceptuales fue tanto espontáneo como planificado a medida que se consolidó el dominio colonial y la hegemonía cultural hispana. Así, la gradual preferencia por tlaxcaltzintli para nombrar a la hostia de modo naturalizado sólo puede explicarse por sus antecedentes prehispánicos y por su popularización entre los nahuas cristianos desde el siglo XVII. No obstante, en tanto que el mundo hispano y mestizo empezó a estar más presente, desde el siglo XVII se hizo mayor uso de formas extranjerizantes como pantzin (con el sentido de Caxtillantlaxcalli), hostia u oztia e incluso santisimo sacramento, presentes entre los nahuas desde el siglo XVI.

En todos los casos, el objetivo evangélico de trasladar la vivencia y pertenencia cristiana, y de asegurar su sujeción a la ortodoxia católica, se enfrentó inicialmente a un temor hacia la confusión que podía surgir de acciones que fundieran los conceptos propios con los conceptos o formas locales, y la dificultad para difundir elementos propios sin un claro equivalente en la comunidad a convertir. No lograr la transferencia traductiva del cristianismo podía generar desviaciones heréticas o reavivar el sentimiento de resistencia y renovación de las religiones locales. Por esta razón, esta traducción transcultural requería de un conocimiento preciso de la lengua y su cultura, y especialmente de sus prácticas rituales y su pensamiento religioso.

El resultado fue un lenguaje litúrgico en náhuatl cuyos términos fueran unívocos, aunque en algún caso se partiera de elementos del lenguaje común. Así, para el caso de la eucaristía, sobre los alimentos y su valor cotidiano se pudo establecer la fusión de sentidos para identificar un alimento básico, pero para una bebida cuya sustancia y relieve permitiera la metáfora de la sangre no se encontró un elemento autóctono equivalente, y los que tenían cierta semejanza conceptual estaban demasiado asocia- 
dos a ciertas divinidades y númenes demonizados. Esto, y que la comunión fuera en una sola especie, contribuyó a que la palabra vino o huino se asentara como solución extranjerizante. Este repertorio de términos confluyen en el siglo XIX como denominaciones populares que en el contexto eucarístico se resignificó como una especie, un fructus objeto de devoción y comunión. Así, se consideraría un fermentum de la unidad de la comunidad cristiana entre españoles y naturales en el contexto novohispano y luego en el México independiente.

\section{Referencias}

Acosta, José de. 2003. Historia natural y moral de las Indias. Madrid: Dastin.

Almeida, Teodoro de. 1839. Piadoso Devocionario en honor del Sagrado Corazón de Jesús. Orizaba: Imprenta de Felis Mendarte.

Ángeles, Manuel Valentín. 1883. Brevísima explicación de los principales misterios de Nuestra Santa Religión Católica. Tepoztlán: Imprenta de Rojas y Compañía.

Anónimo. 1835. Explicación clara y sucinta de los principales misterios de nuestra santa fé. Puebla: Imprenta del Hospital de San Pedro.

Anónimo. 1840. Compendio del Confesionario en mexicano y castellano para que los que ignoren el primero puedan á lo menos en los casos de necesidad administrar á los indígenas el Sacramento de la Penitencia. Puebla: Imprenta antigua del Portal de las Flores.

Báez-Jorge, Félix. 2011. Debates en torno a lo sagrado. Religión popular y hegemonía clerical en el México indígena. Xalapa: Universidad Veracruzana.

—. 2013. ¿Quiénes son aqui los dioses verdaderos? Religiosidad indígena y hagiografias populares. Xalapa: Universidad Veracruzana.

Bartolomé, Miguel Ángel y Alicia M. Barabás. 1982. Tierra de la palabra. Historia y etnografia de los chatinos de Oaxaca. México: Instituto Nacional de Antropología e Historia.

Basurko, Xabier. 2006. Historia de la Liturgia. Barcelona: Centre de Pastoral Litúrgica.

Berman, Antoine. 1984. L'épreuve de l'étranger. Culture et traduction dans l'Allemagne romantique. París: Gallimard.

Bueno García, Antonio, ed. 2007. La labor de traducción de los agustinos españoles. Valladolid: Editorial Estudio Agustiniano.

—, coord. 2013. La labor de traducción de los franciscanos. Madrid: Editorial Cisneros.

Córdoba, Pedro de. 1550. Doctrina christiana en lengua Española y Mexicana: hecha por los religiosos de la orden de sancto Domingo. Agora nueuamente corregida y enmendada. México: Casa de Juan de Pablos.

Fountain, Catherine. 2015. "Transculturation, Assimilation, and Appropriation in the Missionary Representation of Nahuatl", en Colonialism and Missionary Linguistics, Klaus Zimmermann y Birte Kellermeier-Rehbein, eds., pp. 177-198. Berlín, Boston: De Gruyter.

Durán, Diego. 2002. Historia de las indias de Nueva España e Islas de Tierra Firme. Tomo I. México: Consejo Nacional para la Cultura y las Artes.

Gante, Pedro de. 1553. Doctrina christiana en lengua mexicana. México: Casa de Juan de Pablos.

Hurtado Albir, Amparo. 2008. Traducción y traductología. Introducción a la traductología. Madrid: Ediciones Cátedra.

Kelly, Louis G. 1979. The True Interpreter. A History of Translation Theory and Practice in the West. Oxford: Basil Blackwell. 
León, Martín de. 1611. Camino del cielo en lengva mexicana, con todos los requisitos necessarios para conseguir este fin. México: Imprenta de Diego López Dávalos.

Lockhart, James. 1991. Nahuas and Spaniards. Postconquest Central Mexican History and Philology. Standford: Standford University Press.

- 1999. Los nahuas después de la Conquista. Historia social y cultural de la población indígena del México central, siglos XVI-XVIII. México: Fondo de Cultura Económica.

McAfee, Byron. 1953. «Danza de la Gran Conquista». Tlalocan 3 (3): 246-273.

Mendieta, Gerónimo de. 2002. Historia eclesiástica indiana. Tomo 1. México: Consejo Nacional para la Cultura y las Artes.

Mijangos, Juan de. 1607. Espejo Divino en lengua mexicana, en que pueden verse los padres y tomar documento para acertar a doctrinar bien a sus hijos y aficionallos a las virtudes. México: Imprenta de Diego López Dávalos.

- 1624. Primera parte del sermonario dominical, y sanctoral, en lengva mexicana. México: Imprenta del Licenciado Iuan de Alcaçar.

Molina, Alonso de. 1555. Aqui comiença un vocabulario de la lengua Castellana y Mexicana. México: Casa de Juan de Pablos.

- 1571a. Vocabulario en lengua castellana y mexicana. México: Casa de Antonio de Spinosa.

—. 1571b. Vocabulario en lengua mexicana y castellana. México: Casa de Antonio de Spinosa.

- 1578. Doctrina Christiana en lengua Mexicana muy necesaria: en la qual se contiene todos los principales mysterios de nuestra Sancta Fee católica. México: Casa de Pedro Ocharte.

Motolinia, Toribio de Benavente. 2001 (1540). Historia de los indios de la Nueva España. Relación de los ritos antiguos, idolatrías y sacrificios de los indios de la Nueva España, y de la maravillosa conversión que Dios en ellos ha obrado. México: Editorial Porrúa.

Murillo Gallegos, Verónica, Krisztina Zimányi y Anna Maria D’Amore. 2018. “Traducción, evangelización y negociación lingüística: una exploración interdisciplinaria”. Mutatis Mutandis 11 (1): 24-51. https://doi.org/10.17533/udea.mut.v11n1a02

Nebrija, Antonio de. 1492. Dictionarium latino hispanicum. Salamanca: Juan de Porras impresor.

Olko, Justyna y Julia Madajczak. 2019. «An Animating Principle in Confrontation with Christianity? De(re)constructing the Nahua "Soul"». Ancient Mesoamerica 30 (1): 75 88. https://doi.org/10.1017/S0956536118000329.

Olmos, Andrés de. 1993 (1547). Arte de la lengua mexicana. Libro facsímil. Estudio introductorio y paleografía Ascensión Hernández de León Portilla y Miguel León Portilla. Madrid: Ediciones de Cultura Hispánica.

Paredes, Ignacio de. 1758. Catecismo Mexicano, que contiene toda la Doctrina Christiana con todas sus Declaraciones: en que el Ministro de Almas hallarà, lo que á estas debe enseñar: y estas hallarán lo que, para salvarse, deben saber, creer, y observar. Dispusolo primeramente en Castellano el Padre Geronymo de Ripalda de la Compañia de Jesus. México: Imprenta de la Bibliotheca Mexicana.

-. 1759. Promptuario Manual Mexicano. México: Imprenta de la Bibliotheca Mexicana.

Parodi, Claudia. 2009. «La semántica cultural: un modelo de contacto lingüístico y Las Casas», en Visiones del encuentro de dos mundos en América: lengua, cultura, traducción y transculturación, Karen Dakin, Mercedes Montes de Oca y Claudia Parodi, eds., pp. 19-45. México: Seminario de Lenguas Indígenas, Centro de Estudios Literarios, Instituto de Investigaciones Filológicas, Universidad Nacional Autónoma de México y Centro de Estudios Coloniales Iberoamericanos, Universidad de California en Los Ángeles.

Payás Puigarnau, Gertrudis. 2010. El revés del tapiz. Traducción y discurso de identidad en la Nueva España (1521-1821). Madrid: Iberoamericana. 
Ricard, Robert. 2001. La conquista espiritual de México. $2^{\text {a }}$ edición, $6^{\text {a }}$ reimpresión. México: Fondo de Cultura Económica.

Rojas Rabiela, Teresa, Elsa Leticia Rea López y Constantino Medina Lima. 1999. Vidas y bienes olvidados. Testamentos indígenas novohispanos, Vol. 2. México: Centro de Investigaciones y Estudios Superiores en Antropología Social.

Sabio Pinilla, José Antonio. 2006. «La metodología en historia de la traducción: estado de la cuestión». Sendebar. Revista de la Facultad de Traducción e Interpretación de la Universidad de Granada 17: 21-47.

Sahagún, Bernardino de. 1558. Primeros memoriales (Ms.). Biblioteca Digital Mexicana. $\mathrm{http} / /$ bdmx.mx/documento/galeria/bernardino-sahagun-codices-matritenses/fo_06.

-. 2006. Historia general de las cosas de la Nueva España. México: Editorial Porrúa.

Sell, Barry D. y Louise M. Burkhart. 2012. Nahuatl Theater: Nahua Christians in Performance. Vol. 4. Norman: University of Oklahoma Press.

Sullivan, Thelma D. 1998. Compendio de la gramática náhuatl. México: Instituto de Investigaciones Históricas, Universidad Nacional Autónoma de México.

Tavárez, David. 2000. «Naming the Trinity: From Ideologies of Translation to Dialectics of Reception in Colonial Nahua Texts, 1547-1771». Colonial Latin American Review 9 (1): 21-47.

Trinidad Palma, Miguel. 1886. Catecismo de la Doctrina Cristiana por el padre Gerónimo de Ripalda traducida al idioma mejicano. Puebla: Imprenta de M. Corona.

Vázquez Gastelu, Antonio. 1860. Catecismo breve que precisamente debe saber el cristiano. Puebla: Imprenta de José María Rivera.

Vega Cernuda, Miguel Ángel, ed. 2012. Traductores hispanos de la orden franciscana en Hispanoamérica. Lima: Universidad Ricardo Palma.

Velásquez de Cárdenas y León, Carlos Celedonio. 1761. Breve practica, y regimen del confesionario de indios, en mexicano, y castellano, para instruccion del confessor principiante, habilitacion y examen del penitente. México: Imprenta de la Bibliotheca Mexicana.

Zamora Ramírez, Elena Irene. 2012. «Los problemas de traducción del catecismo en América en el siglo XVI», en Traductores hispanos de la orden franciscana en Hispanoamérica, Miguel Ángel Vega Cernuda, ed., pp. 103-123. Lima: Universidad Ricardo Palma.

Zimmermann, Klaus. 2005. «Traducción, préstamos y teoría del lenguaje: la práctica transcultural de los lingüistas misioneros en el México del siglo XVI», en Missionary Linguistics / Lingüística Misionera II: Orthography and Phonology, Otto Zwartjes y Cristina Altman, eds., pp. 107-136. Amsterdam, Filadelfia: Johns Benjamins.

Zimmermann, Klaus y Birte Kellermeier-Rehbein, eds. 2015. Colonialism and Missionary Linguistics. Berlín, Boston: De Gruyter.

Zwartjes, Otto. 2016. «Colonial Missionaries’ Translation Concepts and Practices: Semantics and Grammar», en La transmisión de conceptos cristianos a las lenguas amerindias: Estudios sobre textos y contextos de la época colonial, Sabine Dedenbach-Salazar Sáenz, ed., pp. 43-76. Sankt Augustin: Academia Verlag.

Zwartjes Otto y Even Hovdhaugen, eds. 2004. Missionary linguistics / Lingüistica misionera. Amsterdam: John Benjamins. https://doi.org/10.1075/sihols.106. 